\title{
Estimating the Number of American Children Living in Partner-Violent Families
}

\author{
Renee McDonald and Ernest N. Jouriles \\ Southern Methodist University
}

\author{
Suhasini Ramisetty-Mikler and Raul Caetano \\ University of Texas Health Science Center, Dallas \\ Regional Campus
}

\author{
Charles E. Green \\ University of Houston
}

\begin{abstract}
The number of American children living in partner-violent households was estimated from a nationally representative sample of 1,615 dual-parent households. Approximately 15.5 million American children were estimated to live in families in which partner violence had occurred at least once in the previous year, with 7 million estimated to live in families in which severe partner violence had occurred. The prevalence of partner violence was higher among couples with children than among couples without children.
\end{abstract}

Keywords: domestic violence, intimate partner violence, children, prevalence

It is becoming increasingly clear that physical violence between adult intimate partners increases children's risk for a variety of adjustment difficulties. For example, children living in households characterized by frequent and severe partner violence exhibit more behavioral and emotional problems than children in nonviolent households (Jouriles, Norwood, McDonald, \& Peters, 2001; Margolin \& Gordis, 2000). Children's exposure to adult physical aggression in experimental laboratory research leads to short-term behavioral disruptions and distress (Cummings, Vogel, Cummings, \& El-Sheikh, 1989; Laumakis, Margolin, \& John, 1998), with repeated exposure theorized to result in more long-standing adjustment difficulties (Cummings \& Davies, 1994). Adults who report childhood exposure to partner

Renee McDonald and Ernest N. Jouriles, Department of Psychology, Southern Methodist University; Suhasini RamisettyMikler and Raul Caetano, School of Public Health, University of Texas Health Science Center, Dallas Regional Campus; Charles E. Green, Department of Psychology, University of Houston.

The work of Renee McDonald and Ernest N. Jouriles on this research was supported by Grant R01-MH62064 from the National Institute of Mental Health and Grant 98-WT-VX- from the National Institute of Justice, Office of Justice Programs, U.S. Department of Justice. Points of view in this report are those of the authors and do not necessarily represent the official position of the U.S. Department of Justice. The work of Suhasini RamisettyMikler and Raul Caetano on this research was supported by Grant R37-AA10908 from the National Institute on Alcohol Abuse and Alcoholism to the School of Public Health, University of Texas Health Science Center.

Correspondence concerning this article should be addressed to Renee McDonald, Department of Psychology, Southern Methodist University, P.O. Box 750442, Dallas, TX 75275-0442. E-mail: rmcdonal@smu.edu violence experience greater difficulties in interpersonal relationships and more emotional problems than those who report no such exposure (Stith, Rosen, \& Middleton, 2000). In short, converging results from disparate studies make it increasingly clear that partner violence is deleterious for children.

The magnitude of this problem in the United States, however, is not quite so clear. A few investigators have derived estimates of the number of American children living in partner-violent families (e.g., Carlson, 1984; Holden, 1998; Straus, 1992). However, each of the estimates is constrained by problems in its derivation. Carlson's (1984) estimate, which was the first and is perhaps the most widely cited, illustrates some of these problems. Carlson estimated that approximately 3.3 million children in the United States are exposed to intimate partner violence each year. Extrapolated from the 1975 National Family Violence Survey (Straus, Gelles, \& Steinmetz, 1980) and U.S. Census data, this estimate was limited to households with a child between 3 and 17 years of age. The omission of very young children is noteworthy because children 5 years old or younger appear to be disproportionately represented among families characterized by partner violence (Fantuzzo, Boruch, Beriama, Atkins, \& Marcus, 1997). Carlson's estimate is also based on a single partner's report of partner violence. Because disagreement between partners on the occurrence of such violence is common, estimates based on a single partner's report are considered to be of lower quality (Caetano, Schafer, Field, \& Nelson, 2002; Jouriles \& O’Leary, 1985). The assessment was also limited to acts of severe violence (e.g., punching, kicking, threat or use of weapons), which, in comparison to other acts of partner violence (e.g., pushes, grabs, shoves), are considerably less common (Schafer, Caetano, \& Clark, 1998; Straus \& Gelles, 1990). Although the bulk of the data linking partner violence with child 
problems involves samples characterized by frequent and severe violence (Jouriles, Norwood, et al., 2001; Margolin \& Gordis, 2000), "minor" violence has also been associated with child adjustment difficulties (e.g., Fantuzzo et al., 1991). Arguably, such violence should be considered when estimating the number of children living in partner-violent families. In fairness to Carlson, her estimate was offered in the context of an early literature review, presented with clear caveats, and offered in the absence of more direct data. Yet, her projection is still one of very few available and is regularly cited by researchers and policymakers.

The purpose of this study is to provide an updated, scientifically sound estimate of the number of American children living in partner-violent households. Based on a secondary analysis of a large, national, multistage probability sample of married and cohabiting couples, the estimate reflects intimate partner violence in dual-parent households with children. The sample includes couples with children (ages 0-17 years) living in the household, and the measure of violence is derived from both partners' reports. In addition, as there is no universally accepted definition of partner violence, and minor and severe partner violence both have been associated with child difficulties, we report both, and we report both male violence and female violence.

\section{Method}

\section{Participants and Data Collection}

Participants were selected through a multistage area probability sampling procedure from individuals 18 years of age or older in households in the 48 contiguous states. A total of 4,925 participants (main participants) were interviewed in 1995, with a response rate of $77 \%$. The sample includes oversamples of Blacks $(n=1,588)$ and Hispanics $(n=1,585)$. For this study, only married or cohabiting couples were included. All couples 18 years of age and older living in these randomly selected households were eligible for inclusion. This process identified 1,925 couples, of which 1,635 couples completed the interview, yielding a response rate of $85 \%$ (the 1,635 couples in which both partners were successfully interviewed, divided by the 1,925 eligible couples). Additional details on the study population and data collection are presented elsewhere (Caetano \& Clark, 1998; Schafer et al., 1998).

Trained interviewers conducted interviews with both members of each couple independently in their homes. The main respondent participated in a face-to-face interview that took approximately 1 $\mathrm{hr}$ to complete, whereas the spouse or partner responded to a briefer (approximately $20 \mathrm{~min}$ ) version of the interview. Approximately $57 \%$ of those who completed the 1-hr interview were male. Spanish-speaking participants were given the choice to be interviewed in either English or Spanish. Before beginning, the interviewer made sure that the interview would be conducted in private. Interviewers rated each interview for overall quality (questionable, generally adequate, or high) on the basis of impressions of participants cooperation and interest and whether someone else (e.g., partner, other family member, friend) interrupted the interview. In total, interviews from 20 couples were excluded (4 were same-sex couples and 16 were considered questionable in quality). Thus, the final sample for the present study included 1,615 married or cohabiting couples: 555 White couples, 357 Black couples, 527 Hispanic couples, and 176 mixed/other couples (partners who were not of the same ethnicity or couples in which one or both were of mixed ethnicity).

\section{Measures}

Partner violence. Participants were asked about the occurrence of 11 violent behaviors that they may have perpetrated against their partners, or that their partners may have perpetrated against them, during the past year. The items were adapted from the Conflict Tactics Scale, Form R (CTS; Straus, 1990) and included "threw something"; "pushed, grabbed or shoved"; "slapped"; "kicked, bit or hit"; "hit or tried to hit with something"; "beat up"; "choked"; "burned or scalded"; "forced sex"; "threatened with a knife or gun"; "used a knife or gun." Because of survey time constraints, occurrence (yes/no) rather than frequency data were collected. In accord with previously published reports (e.g., Leonard \& Quigley, 1999; McDonald, Jouriles, Norwood, Ware, \& Ezell, 2000; O'Leary et al., 1989), couples were categorized as violent if either member reported the occurrence of 1 or more of any of the 11 acts of violence. Couples were categorized as nonviolent if both members reported no violent acts. Similarly, within each couple classified as violent, the man was classified as violent if he or his partner reported that he had committed any of the 11 acts of violence and was classified as nonviolent if both partners indicated that he had not engaged in any of the violent acts. The woman was classified in this fashion as well.

Severity of violence was also measured. In accord with previous reports (e.g., Straus et al., 1980; Straus \& Gelles, 1990), the couple was categorized as reporting severe violence if either partner reported the occurrence of one or more of the following acts: "kicked, bit or hit"; "hit or tried to hit with something"; "beat up"; "choked"; "burned or scalded"; "forced sex"; "threatened with a knife or gun"; "used a knife or gun." The males and females composing each violent couple were also each classified as having engaged in severe violence or not. This classification of severe violence is consistent with the results of a number of factor analytic studies of the CTS (e.g., Barling, O'Leary, Jouriles, Vivian, \& MacEwan, 1987; Pan, Neidig, \& O'Leary, 1994).

Presence of children in the home. The presence of children ages $0-17$ who resided in the couple's home was obtained for each participating couple.

\section{Data Analysis}

Because of the multistage sample design, standard errors were expected to be larger than those observed with simple random samples. We used Software for Survey Data Analysis (Research Triangle Institute, 2002) to correct for this effect, and we weighted the data to correct for probability of selection into the sample and nonresponse rates. In addition, we calculated a poststratification weight to adjust the sample to known population distributions on certain demographic variables (ethnicity of the household informant, metropolitan status, and region of the country). For calculating the number of children living in partner-violent married and cohabiting households, we used the poststratification weights to adjust the ethnic composition of the sample to reflect the U.S. population.

Data from the 2001 Current Population Survey (CPS) were used to estimate the number of children in the United States exposed to partner violence over the course of a year. According to the CPS, there were 61,939,000 married or cohabiting couples in the United States in 2001, and there were approximately 52,700,000 children living in married or cohabiting dual-parent households (U.S. Cen- 
sus Bureau, 2003; Detailed Tables FG3, UC1, and C3). ${ }^{1}$ The number of children living in partner-violent households was calculated with the following formula:

The proportion of couples in the sample in which partner violence occurred $\times$ the proportion of violent couples in the sample with at least one child living in the home $\times$ the average number of children per violent couple with children living in the home $\times$ the number of married and cohabiting couples in the United States.

This formula was used to estimate the number of children living in families in which any partner violence occurred and in which severe intimate partner violence occurred over the 12-month period preceding the assessment. The formula was also used to estimate the number of children living in families in which maleto-female and female-to-male violence had occurred.

\section{Results}

\section{Prevalence of Partner Violence}

The prevalence in the previous year for each act of partner violence, for any violence, and for severe violence is presented in Table 1. Prevalence rates are also presented separately for male and female partner violence. Partner violence was reported by $21.45 \%$ of couples, with male-tofemale violence in $13.66 \%$ and female-to-male violence in $18.20 \%$ of couples. Severe partner violence was reported by $8.64 \%$ of couples, with severe male-to-female partner violence in $3.63 \%$ of couples and severe female-to-male partner violence in $7.52 \%$ of couples.

\section{Presence of Children in Partner-Violent Families}

Any violence. Among the $21.45 \%$ of couples in which partner violence was reported to have occurred, $59.02 \%$ had children living in the household. These figures indicate that $12.66 \%(21.45 \% \times 59.02 \%)$ of the couples in the total sample reported the occurrence of intimate partner violence and had children living in the home. There were 1.98 children, on average, in households with children and in which intimate partner violence occurred. When extrapolated to the 2001 U.S. population, this translates to approximately 15.5 million children $(21.45 \% \times 59.02 \% \times 1.98 \times$ $61,939,000)$ living in married or cohabiting households in which partner violence occurred. This figure represents $29.4 \%$ of the 52,700,000 children in the United States who live in married or cohabiting households. These calculations are summarized in Table 2, as are the corresponding calculations for severe violence and for male and female violence.

Severe violence. For the entire sample, $8.64 \%$ of couples reported at least one incident of severe partner violence during the previous year; $62.57 \%$ of these couples had children living in the household. Thus, $5.41 \%(8.64 \% \times$ $62.57 \%$ ) of couples reported severe partner violence and had children in the home. There was an average of 2.10 children per household characterized by both severe partner violence and the presence of children. When applied to the 2001 U.S. population, this yields approximately 7 million children $(8.64 \% \times 62.57 \% \times 2.10 \times 61,939,000)$ - or
$13.3 \%$ of the $52,700,000$ children in married or cohabiting households-living in homes in which severe partner violence occurred.

Male-to-female and female-to-male partner violence. As indicated in Table 2, $13.66 \%$ of couples reported maleto-female partner violence. Among these, $63.14 \%$ had children living in the home, with an average of 2.01 children per home in which male-to-female violence occurred. Thus, approximately 10.7 million children $(13.66 \% \times 63.14 \% \times$ $2.01 \times 61,939,000$ ), or $20.4 \%$ of those in a married or cohabiting household, lived in homes in which male-tofemale partner violence occurred. The corresponding figure for severe male-to-female violence is 2.3 million, or $4.3 \%$ of U.S. children in married or cohabiting households.

Female-to-male partner violence was reported to have occurred in $18.20 \%$ of couples. Among these, $61.60 \%$ had children living in the home, with an average of 1.98 children per household in which female-to-male partner violence occurred. Thus, approximately 13.8 million U.S. children, or $26.1 \%$, lived in married or cohabiting households in which female-to-male partner violence occurred. Approximately 6 million, or $11.4 \%$, lived in families in which severe female-to-male partner violence occurred.

Presence versus absence of children in partner-violent families. An inspection of Table 2 suggests that couples with children may be more likely than couples without children to report partner violence. Among nonviolent couples, $44.04 \%$ had children living in the home. As stated above, $59.02 \%$ of couples reporting any partner violence had children living in the home. These proportions differed significantly, $\chi^{2}(1, N=1,614)=8.3, p=.004$. The proportion of nonviolent couples with children also differed from the proportion of violent couples with children who reported severe violence, $62.57 \%, \chi^{2}(1, N=1,614)=9.1$, $p=.01$; male-to-female partner violence, $63.14 \%, \chi^{2}(1$, $N=1,614)=11.7, p=.0007$; and female-to-male partner violence, $61.60 \%, \chi^{2}(1, N=1,614)=11.4, p=.0008$.

\section{Discussion}

The results of this study suggest that approximately 15.5 million American children live in dual-parent households in which intimate partner violence has occurred within the past year, with approximately 7 million living in households in which severe partner violence has occurred. This means that $29.4 \%$ of children in dual-parent homes live in a family in which partner violence has recently occurred, and $13.3 \%$ live in a family in which severe partner violence has recently occurred. Although greater in magnitude than previous estimates, these findings nonetheless very likely underestimate the true number of children in partner-violent families in the United States. For example, the number of children in partner-violent families among the over 20 mil-

\footnotetext{
${ }^{1}$ Because of social desirability factors operating to suppress reporting of unmarried cohabitation, data on cohabiting couples are believed to underestimate their actual prevalence in the U.S. population.
} 
Table 1

Prevalence of Partner-Violent Acts Committed During the Past Year Within Couples and Separately for Men and Women

\begin{tabular}{lccc}
\hline \multicolumn{1}{c}{ Violent act } & Couple & Male-to-female & Female-to-male \\
\hline 1. Threw something & 12.9 & 4.9 & 11.6 \\
2. Pushed, grabbed, or shoved & 15.6 & 11.2 & 12.2 \\
3. Slapped & 6.8 & 2.5 & 5.6 \\
4. Kicked, bit, or hit & 4.9 & 1.8 & 4.3 \\
5. Hit or tried to hit with something & 6.4 & 2.0 & 5.6 \\
6. Beat up & 0.8 & 0.5 & 0.3 \\
7. Choked & 0.9 & 0.7 & 0.3 \\
8. Burned or scalded & 0.5 & 0.3 & 0.1 \\
9. Forced sex & 1.0 & 0.7 & 0.6 \\
10. Threatened with a knife or gun & 1.1 & 0.4 & 0.9 \\
11. Used a knife or gun & 0.4 & 0.3 & 0.1 \\
Any violence & 21.45 & 13.66 & 18.20 \\
Severe violence & 8.64 & 3.63 & 7.52 \\
\hline
\end{tabular}

Note. $\quad$ Any violence $=$ one or more of items $1-11$ reported; severe violence $=$ one or more of items 4-11 reported.

lion children (U.S. Census Bureau, 2003; Detailed Table C3) in households that are not headed by married or cohabiting parents (e.g., single-parent households, households in which children live with grandparents, foster homes or homes with other guardianship arrangements, same-sex dual-parent households) is unknown and not included in our estimate.

The number of children estimated to live in partnerviolent homes is higher in this research than in previous research (e.g., Carlson, 1984). In fact, the 1-year estimate of 15.5 million is comparable to or higher than estimates (on the basis of retrospective data collected from adults) of the prevalence of exposure to partner violence during all of childhood and adolescence (e.g., Holden, 1998; Straus, 1992). The higher estimates in this study are likely attributable to a number of factors, including the use of multiple informants of partner violence, the inclusion of a wider age range of children in the sample, the assessment of a broader range of acts of partner violence, and an increase in the U.S. population. When considered in light of evidence that exposure to partner violence elevates risk for a variety of child problems (Jouriles, Norwood, et al., 2001; Margolin \& Gordis, 2000), this research suggests that the scope of this problem may be considerably larger than previously thought. It is prudent to remember that much of the research linking partner violence with child problems has been based on samples of children living in families characterized by frequent and severe violence (Jouriles, Norwood, et al., 2001; Margolin \& Gordis, 2000). However, there is accumulating evidence that even low levels of partner violence are associated with increased risk for child problems (e.g., Fantuzzo et al., 1991). If, as this research suggests, almost $30 \%$ of children live in homes in which partner violence occurs, then understanding the magnitude and nature of the risks it presents for children is important for informing policy and intervention development. Setting aside questions of the risk entailed by low levels of partner violence, it is noteworthy that in the present research, the estimate of children living in families in which severe partner violence occurred was twice as high as has been previously estimated. Indeed, almost half of the children in the partner-

Table 2

Estimating the Number of Children Living in Partner-Violent Households

\begin{tabular}{|c|c|c|c|c|c|c|}
\hline \multirow[b]{2}{*}{ Data description } & \multicolumn{2}{|c|}{$\begin{array}{l}\text { Violence by } \\
\text { either partner }\end{array}$} & \multicolumn{2}{|c|}{$\begin{array}{l}\text { Violence by } \\
\text { men }\end{array}$} & \multicolumn{2}{|c|}{$\begin{array}{l}\text { Violence by } \\
\text { women }\end{array}$} \\
\hline & Any & Severe & Any & Severe & Any & Severe \\
\hline 1. Couples in total sample reporting partner violence $(\%)$ & 21.45 & 8.64 & 13.66 & 3.63 & 18.20 & 7.52 \\
\hline 2. Among those reporting partner violence, the proportion with & 5902 & 6257 & 63.14 & 58.40 & 6160 & 6160 \\
\hline 3. In the total sample, couples reporting violence with children $(\%)^{\mathrm{a}}$ & 12.66 & 5.41 & 8.62 & 2.10 & 11.20 & 4.63 \\
\hline $\begin{array}{l}\text { 4. Average no. of children per dual-parent violent household with } \\
\text { children } \\
\text { 5. No. of children in violent households (in millions) } \\
\text { 6. Children in violent households }(\%)^{\mathrm{c}}\end{array}$ & $\begin{array}{l}1.98 \\
15.5 \\
29.4\end{array}$ & $\begin{array}{c}2.10 \\
7.0 \\
13.3\end{array}$ & $\begin{array}{c}2.01 \\
10.7 \\
20.4\end{array}$ & $\begin{array}{l}1.74 \\
2.3 \\
4.3\end{array}$ & $\begin{array}{l}1.98 \\
13.8 \\
26.1\end{array}$ & $\begin{array}{c}2.10 \\
6.0 \\
11.4\end{array}$ \\
\hline
\end{tabular}

Note. Number of married/cohabiting couples in the United States in $2001=61,939,000$; number of children in the United States in 2001 who live in married/cohabiting households $=52,700,000$.

${ }^{\mathrm{a}}$ Row $3=$ Row $1 \times$ Row $2 .{ }^{\mathrm{b}}$ Row $5=$ Row $3 \times 61,939,000 \times$ Row $4 .{ }^{\mathrm{c}}$ Row $6=$ Row 5/52,700,000. 
violent families lived in families in which severe partner violence had occurred.

As expected from previous research with this and other community samples (Archer, 2000), differences were observed in the rates of male and female partner violence, with female violence occurring more frequently. There is very little research on the relative risk to children of male versus female partner violence. In some populations or settings (e.g., shelters for victims of domestic violence, batterer treatment programs), it may be clear that one partner's violence poses a greater risk for children. It might also be inferred, given the different consequences of male versus female violence (Archer, 2000) that male violence is more detrimental to children. Again, however, in unselected samples (e.g., community samples), very little is known about how, or whether, male and female violence differentially influence children's adjustment.

The results of this study also indicate that rates of intimate partner violence are higher among couples with children than those without children. This finding is consistent with research on families in which partner violence is reported to the police (Fantuzzo et al., 1997) and in medical practice samples (Bradley, Smith, Long, \& O’Dowd, 2002). From a clinical perspective, this knowledge can be important and useful. Specifically, the fact that children often are part of partner-violent families should be considered in family assessments and in the design and implementation of interventions for partner violence. For example, the possible involvement of children in violent episodes needs to be considered in the assessment and treatment of families in which intimate partner violence occurs. Similarly, the possible deleterious effects on children of intervention strategies for their parents' partner violence bear consideration.

This study has a number of limitations. Although it provides evidence that a considerable number of American children live in families in which physical violence between married or cohabiting partners occurs, we do not have data on the frequency, context, or consequences of the violence. Such data would inform our understanding of the violence reported in this study. However, it should be noted that versions of the violence measure used in this study have also been very widely used in the research documenting links between partner violence and child problems. That is, associations between partner violence and child problems have been obtained regardless of the context and consequences of the violence. Another possible limitation is that interviews for this study were conducted in individuals' homes, rather than in a lab. The influence of the home setting on interview data is unknown, but it is likely that the influence of variables related to the home setting (e.g., the presence of other family members at home but in other rooms during the interview; participants' concerns about potential conflict or violence as a consequence of the interviews) would have resulted in underreporting of violence, rendering our estimate a conservative one. Also, it should be noted that this research did not directly assess children's exposure to intimate partner violence. Although some consider simply living in a partner-violent household to be a form of exposure, it is important to recognize that there are different ways in which children can be exposed to violence (Holden, 2003; Jouriles, McDonald, Norwood, \& Ezell, 2001), and these may be differentially associated with child problems (Fantuzzo et al., 1991; Jouriles et al., 1998). In conclusion, the principal finding of this research, that a sizable proportion of children in the United States live in partner-violent homes, with a great number living in severely violent homes, provides necessary information for researchers and policymakers in the children's public health arena.

\section{References}

Archer, J. (2000). Sex differences in aggression between heterosexual partners: A meta-analytic review. Psychological Bulletin, 126, 651-680.

Barling, J., O’Leary, K. D., Jouriles, E. N., Vivian, D., \& MacEwen, K. E. (1987). Factor similarity of the conflict tactics scales across samples, spouses, and sties: Issues and implications. Journal of Family Violence, 2, 37-54.

Bradley, F., Smith, M., Long, J., \& O’Dowd, T. (2002). Reported frequency of domestic violence: Cross sectional survey of women attending general practice. British Medical Journal, 324, $1-5$.

Caetano, R., \& Clark, C. L. (1998). Trends in alcohol-related problems among whites, blacks, and Hispanics: 1984-1995. Alcohol Clinical Experimental Research, 22, 534-538.

Caetano, R., Schafer, J., Field, C., \& Nelson, S. M. (2002). Agreement on reports of intimate partner violence among White, Black, and Hispanic couples in the United States. Journal of Interpersonal Violence, 17, 1308-1322.

Carlson, B. E. (1984). Children's observations of interpersonal violence. In A. Roberts (Ed.), Battered women and their families (pp. 147-167). New York: Springer.

Cummings, E. M., \& Davies, P. (1994). Children and marital conflict: The impact of family dispute and resolution. New York: Guilford Press.

Cummings, E. M., Vogel, D., Cummings, J. S., \& El-Sheikh, M. (1989). Children's responses to different forms of expression of anger between adults. Child Development, 60, 1392-1404.

Fantuzzo, J. W., Boruch, R., Beriama, A., Atkins, M., \& Marcus, S. (1997). Domestic violence and children: Prevalence and risk in five major U. S. cities. Journal of the American Academy of Child and Adolescent Psychiatry, 36, 116-122.

Fantuzzo, J. W., DePaola, L. M., Lambert, L., Martino, T., Anderson, G., \& Sutton, S. (1991). Effects of interparental violence on the psychological adjustment and competencies of young children. Journal of Consulting and Clinical Psychology, 59, 258 265.

Holden, G. W. (1998). Introduction: The development of research into another consequence of family violence. In G. W. Holden, R. Geffner, \& E. N. Jouriles (Eds.), Children exposed to marital violence: Theory, research, and applied issues (pp. 1-20). Washington, DC: American Psychological Association.

Holden, G. W. (2003). Children exposed to domestic violence and child abuse: Terminology and taxonomy. Clinical Child and Family Psychology Review, 6, 151-160.

Jouriles, E. N., McDonald, R., Norwood, W. D., \& Ezell, E. (2001). Issues and controversies in documenting the prevalence of children's exposure to domestic violence. In S. A. GrahamBermann \& J. L. Edleson (Eds.), Domestic violence in the lives of children: The future of research, intervention, and social policy (pp. 13-34). Washington, DC: American Psychological Association. 
Jouriles, E. N., McDonald, R., Norwood, W. D., Ware, H. S., Spiller, L. C., \& Swank, P. R. (1998). Knives, guns, and interparent violence: Relations with child behavior problems. Journal of Family Psychology, 12, 178-194.

Jouriles, E. N., Norwood, W. D., McDonald, R., \& Peters, B. (2001). Domestic violence and child adjustment. In J. H. Grych \& F. D. Fincham (Eds.), Interparental conflict and child development: Theory, research, and application (pp. 315-336). Cambridge, England: Cambridge University Press.

Jouriles, E. N., \& O'Leary, K. D. (1985). Interspousal reliability of reports of marital violence. Journal of Consulting and Clinical Psychology, 53, 419-421.

Laumakis, M. A., Margolin, G., \& John, R. S. (1998). The emotional, cognitive, and coping responses of preadolescent children to different dimensions of marital conflict. In G. W. Holden, R. Geffner, \& E. N. Jouriles (Eds.), Children exposed to marital violence: Theory, research, and applied issues (pp. 1-20). Washington, DC: American Psychological Association.

Leonard, K. E., \& Quigley, B. M. (1999). Drinking and marital aggression in newlyweds: An event-based analysis of drinking and the occurrence of husband marital aggression. Journal of Studies on Alcohol, 60, 537-545.

Margolin, G., \& Gordis, E. B. (2000). The effects of family and community violence on children. Annual Review of Psychology, 51, 445-479.

McDonald, R., Jouriles, E. N., Norwood, W. D., Ware, H. S., \& Ezell, E. (2000). Husbands' marital violence, general marital discord, and behavior problems among clinic-referred children. Behavior Therapy, 31, 649-665.

O'Leary, K. D., Barling, J., Arias, I., \& Rosenbaum, A. (1989). Prevalence and stability of physical aggression between spouses: A longitudinal analysis. Journal of Consulting and Clinical Psychology, 57, 263-268.

Pan, H. S., Neidig, P. H., \& O’Leary, K. D. (1994). Male-female and aggressor-victim differences in the factor structure of the
Modified Conflict Tactics Scale. Journal of Interpersonal Violence, 9, 366-382.

Research Triangle Institute. (2002). Software for survey data analysis (SUDAAN): Release 8.0 [Computer software]. Research Triangle Park, NC: Author.

Schafer, J., Caetano, R., \& Clark, C. (1998). Rates of intimate partner violence in the United States. American Journal of Public Health, 88, 1701-1704.

Stith, S. M., Rosen, K. H., \& Middleton, K. A. (2000). The intergenerational transmission of spouse abuse: A meta-analysis. Journal of Marriage and the Family, 62, 640-654.

Straus, M. A. (1990). The conflict tactics scales and its critics: An evaluation and new data on reliability and validity. In M. A Straus \& R. J. Gelles (Eds.), Physical violence in American families: Risk factors and adaptations to violence in 8,145 families (pp. 49-73). New Brunswick, NJ: Transaction Publishers.

Straus, M. A. (1992). Children as witness to marital violence: A risk factor for lifelong problems among a nationally representative sample of American men and women. In D. F. Schwarz (Ed.), Children and violence, report of the twenty-third Ross roundtable on critical approaches to common pediatric problems (pp. 98-104). Columbus, OH: Ross Laboratories.

Straus, M. A., \& Gelles, R. J. (1990). Physical violence in American families: Risk factors and adaptations to violence in 8,145 families. New Brunswick, NJ: Transaction Publishers.

Straus, M. A., Gelles, R. J., \& Steinmetz, S. K. (1980). Behind closed doors: Violence in the American family. Garden City, NY: Doubleday Press.

U.S. Census Bureau. (2003, July 17) Children's living arrangements and characteristics: March 2001. Retrieved December 18, 2003, from www.census.gov/population/www/socdemo/hh-fam/ cps2001.html

Received June 16, 2003

Revision received September 2, 2004 Accepted October 26, 2004

\section{E-Mail Notification of Your Latest Issue Online!}

Would you like to know when the next issue of your favorite APA journal will be available online? This service is now available to you. Sign up at http://watson.apa.org/ notify/ and you will be notified by e-mail when issues of interest to you become available! 